\title{
Switching to systemic therapy after locoregional treatment failure: Definition and best timing
}

\author{
Sadahisa Ogasawara ${ }^{1,2, *}$, Yoshihiko Ooka', , Keisuke Koroki', Susumu Maruta', Hiroaki Kanzaki', Kengo Kanayama', \\ Kazufumi Kobayashi, ${ }^{1,2}$, Soichiro Kiyono', Masato Nakamura', Naoya Kanogawa', Tomoko Saito', Takayuki Kondo', \\ Eiichiro Suzuki', Shingo Nakamoto', Akinobu Tawada ${ }^{1,3}$, Tetsuhiro Chiba', Makoto Arai ${ }^{1,3}$, Jun Kato', and Naoya Kato ${ }^{1,2}$ \\ 'Department of Gastroenterology, Graduate School of Medicine, Chiba University, Chiba; ${ }^{T}$ Translational Research and Development \\ Center, Chiba University Hospital, Chiba; ${ }^{3}$ Department of Medical Oncology, Graduate School of Medicine, Chiba University, Chiba, \\ Japan
}

In patients with unresectable hepatocellular carcinoma (HCC) without both macrovascular invasion and extrahepatic metastasis, the initial treatment choice recommended is transarterial chemoembolization (TACE). Before sorafenib came into wide use, TACE had been pointlessly carried out repeatedly. It was in the early 2010s that the concept of TACE refractory was advocated. Two retrospective studies from Japan indicated that conversion from TACE to sorafenib the day after patients were deemed as TACE refractory improved overall survival compared with continued TACE, according to the definition by the Japan Society of Hepatology. Nowadays, phase 3 trials have shown clinical benefits of several novel molecular target agents. Compared with the era of sorafenib, sequential treatments with these molecular target agents have gradually prolonged patients' survival and have become major strategies in patients with HCC. Taking these together, conversion from TACE to systemic therapies at the time of TACE refractory, compared with before, may have a greater impact on survival and may be considered deeper in the decisions-making process in patients with unresectable HCC who are candidate for TACE. Up-to-date information on the concept of TACE refractory is summarized in this review. We believe that the survival of patients with unresectable HCC without both macrovascular invasion and extrahepatic metastasis may be dramatically improved by optimal timing of TACE refractory and switching to systemic therapies. (Clin Mol Hepatol 2020;26:155-162)

Keywords: Carcinoma, Hepatocellular; Liver neoplasms; Patient selection; Sorafenib

\section{INTRODUCTION}

Hepatocellular carcinoma (HCC) is the one of the worst malignancies, where mortality (781,631 deaths) closely parallels inci- dence $\left(841,080\right.$ cases diagnosed). ${ }^{1-3}$ Frequent surveillance is recommended for the high-risk population of patients with HCC, such as those with cirrhosis or hepatitis virus infection, to diagnose the disease at an early stage. ${ }^{2-8}$ Patients with limited tumor

\footnotetext{
Abbreviations:

BCLC, Barcelona Clinic Liver Cancer; BRIDGE, Bridge to Better Outcomes in HCC; CTACE, conventional transarterial chemoembolization; DEB-TACE, drugeluting bead transarterial chemoembilization; EHM, extrahepatic metastasis; HCC, hepatocellular carcinoma; MVI, macrovascular invasion; OPTIMIS, Outcomes of Hepatocellular Carcinoma Patients Treated With Transarterial Chemoembolization and Early, Not Early or Not at All Followed by Sorafenib; OS, overall survival; RESORCE, regorafenib after sorafenib in patients with HCC; TACE, transarterial chemoembilization

*These authors contributed equally to this work.
}

\author{
Corresponding author : Sadahisa Ogasawara \\ Department of Gastroenterology, Graduate School of Medicine, Chiba \\ University, 1-8-1 Inohana, Chuo-ku, Chiba 260-8670, Japan \\ Tel: +81-43-226-2083, Fax: +81-43-226-2088 \\ E-mail: ogasawaras@chiba-u.jp \\ https://orcid.org/0000-0002-6540-9064
}


burden with well liver function are the best candidates for resection. Another alternative treatment option for those with up to three nodules or nodules $3 \mathrm{~cm}$ or smaller (without both macrovascular invasion [MVI] and extrahepatic metastasis [EHM]) is local ablation therapy (radiofrequency ablation or microwave ablation). ${ }^{3-8}$ All over the world, the first-line treatment widely recommended for unresectable HCC without both MVI and EHM is transarterial chemoembolization (TACE), which is a locoregional treatment. ${ }^{3-8}$ Novel molecular target therapies have been proven the effectiveness in phase 3 studies, and thus, several treatment options have become standard systemic therapies for advancedstage HCC or for those tumors progressing to locoregional treatment. ${ }^{9.14}$ However, creating a distinct definition of the timing of switching from locoregional treatment to systemic therapies in patients with HCC is not easy. Thus far, consultation with experts with advanced knowledge is needed when deciding to give up locoregional treatment and switching to systemic therapies in the field. Therefore, the aims of this study were to review the efficacy and limitations of TACE and discuss the most appropriate timing for switching from locoregional treatment to systemic therapies.

\section{RECONSIDERATION OF TACE FROM THE CUR- RENT PERSPECTIVE}

TACE is the most widely used treatment worldwide for unresectable HCC. $2,3,15$ The Bridge to Better Outcomes in HCC (BRIDGE) study, an international large and longitudinal cohort study that included 18,031 patients in 14 countries, indicated that TACE was frequently performed not only for patients with intermediatestage HCC but also for patients with early- or advanced-stage $\mathrm{HCC}$ according to the Barcelona Clinic Liver Cancer (BCLC) staging system. ${ }^{15}$ Looking back at the history of TACE, improved patient survival with TACE compared with best supportive care or suboptional treatments was demonstrated by a meta-analysis of six randomized controlled trials in 2003. ${ }^{16}$ Therefore, both Eastern and Western guidelines have recommended TACE as therapy in patients with intermediate-stage HCC (Table 1)..$^{4-8}$ So far, there are two major TACE techniques, namely, conventional TACE (CTACE), which uses a lipiodol mixture with chemotherapy agents, and TACE with drug-eluting bead (DEB-TACE). ${ }^{17-24}$ In one randomized controlled trial comparing CTACE and DEB-TACE, no difference was found in tumor response and time to progression. ${ }^{24}$ The decision whether to undergo CTACE or DEB-TACE seems to be dependent on the medical situation of each country or the institution.

Institutions with a high volume of patients or substantial experiences have advanced TACE techniques. ${ }^{20,25-28}$ So far, cone-beam or interventional radiology angiography computed tomography systems can construct three-dimensional reconstruction of arteries and support superselective TACE. ${ }^{29-31}$ Moreover, inserting a catheter into the tumor feeding arteries superselectively leads to the prevention of liver function and reduction in negative side effects. Using a large cohort of patients $(n=815)$, Yamakado et al. ${ }^{32}$ reported that selective TACE contributed to survival outcomes in patients who received TACE (hazard ratio, 0.68; 95\% confidence interval, $0.48-0.97 ; P=0.033$ ). Another systemic review indicated that the most common adverse events were related to the postembolization syndrome, including increased liver enzyme $(18.1 \%)$, fever $(17.2 \%)$, abdominal pain (11.0\%), vomiting (6.0\%), and nausea $(1.7 \%) .{ }^{20}$ In a recent randomized placebo-controlled trial, ${ }^{33}$ it was that indicated prophylactic dexamethasone prevented postembolization syndrome, although validation is required. Current treatment-related death rate is estimated to be less than $1 \%$ in patients with HCC.

Table 1. Recommendations for transarterial chemoembilization in guidelines all over the world

\begin{tabular}{|c|c|}
\hline Guidelines & Recommendations \\
\hline $\begin{array}{l}\text { Asian Pacific Association for the Study of the } \\
\text { Liver (APASL) }(2017)^{4}\end{array}$ & $\begin{array}{l}\text { First line in patients with unresectable, large multifocal HCCs, without vascular invasion or } \\
\text { extrahepatic spread. }\end{array}$ \\
\hline $\begin{array}{l}\text { European Association for the Study of the Liver } \\
\text { (EASL) (2018) }\end{array}$ & $\begin{array}{l}\text { First line in BCLC B patients (not recommended for patients with decompensated liver } \\
\text { disease, advanced liver and/or kidney dysfunction, macroscopic vascular invasion, or } \\
\text { extrahepatic spread). }\end{array}$ \\
\hline $\begin{array}{l}\text { Korean Liver Cancer Association-National } \\
\text { Cancer Center Korea (2019) }\end{array}$ & $\begin{array}{l}\text { Patients with a good performance status without major vascular invasion or extrahepatic } \\
\text { spread who are ineligible for surgical resection and liver transplantation, RFA, or PEIT. }\end{array}$ \\
\hline Japan Society of Hepatology (JSH) (2019) & $\begin{array}{l}\text { Unresectable Child-Pugh A and B patients with one to three nodules }(\geq 3 \mathrm{~cm} \text { ) and more than } \\
\text { four nodules (any size), without both vascular invasion and extrahepatic metastasis. }\end{array}$ \\
\hline
\end{tabular}

HCC, hepatocellular carcinoma; BCLC, Barcelona Clinic Liver Cancer; RFA, radiofrequency ablation; PEIT, percutaneous ethanol injection therapy. 
Sadahisa Ogasawara, et al. Best timing for switching to systemic therapies

A latest systemic review that had, to date, more than 10,000 patients with HCC undergoing TACE documented a $52.3 \%$ objective response, with overall 1-, 2-, 3-, and 5-year survival rates of $70.3 \%, 51.8 \%, 40.4 \%$, and $32.4 \%$, respectively. ${ }^{20}$ Nowadays, the median overall survival (OS) of patients with intermediate-stage HCC who received TACE is suggested to be around 30 months. ${ }^{2}$ In more than half of patients, objective response can be achieved by TACE, and tumor progression may be delayed in these patients. ${ }^{10}$ However, a latest international observation study (the outcomes of HCC patients treated with TACE and early, not early or not at all followed by sorafenib [OPTIMIS] study) found that with repeated TACE, expectation rates of objective response decreased (first TACE: 40\%; second TACE: 26\%; third TACE: 24\%; and fourth TACE: $25 \%)^{34}$

A recent report based on a US database $(n=3,967)^{35}$ demonstrated deterioration of liver function from baseline in the acute period, which persisted in the chronic period (bilirubin, 30\% and 23\%; albumin, 52\% and 31\%; aspartate transaminase, 44\% and 25\%; alanine transaminase, $43 \%$ and 25\%; and prothrombin time, $25 \%$ and $15 \%$, respectively). Hiraoka et al. ${ }^{36}$, using a Japanese multicenter cohort, reported that liver function deteriorated with repeated TACE. It is well known that in patients with HCC, retaining liver function is equally important as removing or controlling tumor. ${ }^{36}$ That is, it is possible to experience decreasing liver function without getting an objective response when continuing TACE without appropriate decisions.

\section{WHAT IS "TACE REFRACTORY"?}

In most cases of unresectable HCC, before the use of sorafenib was approved, treatment with TACE was continued casually. Repeated TACE is associated with increased liver failure and diminishing efficacy. If treatment with TACE is continued without any assessment, the patient loses the opportunity to convert to systemic therapy because of liver function deterioration. ${ }^{37}$ Regarding recommendations or suggestions for patients with unresectable HCC to switch from TACE to systemic therapies, "TACE refractory" is a new-era concept that has been advocated since sorafenib was first used in practice (Table 2). ${ }^{4,538-41}$ It has been suggested that the appropriate timing of switching from TACE to systemic therapies is when repeated TACE is expected to become ineffective, the so-called TACE refractory. Kudo et al. ${ }^{38,39}$, from Japan, published one of the major suggestions on this topic. Their recom-

Table 2. Recommendations/suggestions for switching from transarterial chemoembilization to systemic therapies in patients with unresectable hepatocellular carcinoma without both macrovascular invasion and extrahepatic metastasis

\begin{tabular}{|c|c|}
\hline Guidelines/articles & Recommendations/suggestions \\
\hline Raoul et al. ${ }^{40}$ (2011) & Patients who progress after two cycles of TACE \\
\hline $\begin{array}{l}\text { JSH-LCSGJ criteria } 2014 \text { (so-called the } \\
\text { definition of TACE failure/refractoriness) } \\
(2014)^{39}\end{array}$ & $\begin{array}{l}\text { (1) Intrahepatic lesion } \\
\text { - Two or more consecutive insufficient responses of the treated tumor (viable lesion }>50 \% \text { ) even } \\
\text { after changing the chemotherapeutic agents and/or reanalysis of the feeding artery seen on } \\
\text { response evaluation CT/MRI at 1-3 months after having adequately performed selective TACE } \\
\text { - Two or more consecutive progressions in the liver (tumor number increases as compared } \\
\text { with tumor number before the previous TACE procedure) even after having changed the } \\
\text { chemotherapeutic agents and/or reanalysis of the feeding artery seen on response evaluation } \\
\text { CT/MRI at 1-3 months after having adequately performed selective TACE } \\
\text { (2) Continuous elevation of tumor makers immediately after TACE even though slight transient } \\
\text { decrease in observed } \\
\text { (3) Appearance of vascular invasion } \\
\text { (4) Appearance of extrahepatic spread }\end{array}$ \\
\hline $\begin{array}{l}\text { Asian Pacific Association for the Study of } \\
\text { the Liver (APASL) (2017) }\end{array}$ & $\begin{array}{l}\text { Treatment conversion from TACE to systemic therapy is recommended for patients in whom TACE } \\
\text { is expected to be insufficient. }\end{array}$ \\
\hline Galle et al. ${ }^{41}$ (2017) & $\begin{array}{l}\text { Patients who have never or no longer respond to TACE (treatment stage migration to the right- } \\
\text { hand side on the BCLC staging system). }\end{array}$ \\
\hline $\begin{array}{l}\text { American Association for Study of Liver } \\
\text { Disease (AASLD) (2018) }\end{array}$ & $\begin{array}{l}\text { Patients who are ineligible for or progress after TACE/TARE should be considered for systemic } \\
\text { therapy. }\end{array}$ \\
\hline Japan Society of Hepatology (JSH) (2019) ${ }^{8}$ & Molecular target therapy is recommended as second-line therapy for up to four intrahepatic nodules. \\
\hline
\end{tabular}


mendation was validated in two retrospective studies that showed that patients with intermediate-stage HCC whose disease was refractory to TACE and who switched to sorafenib had prolonged OS compared with those who continued TACE (first trial: 25.4 vs. 11.5 months, $P=0.003$; second trial: 24.7 vs. 13.6 months, $P=0.002){ }^{42,43}$ Currently, a large cohort global prospective observation study (OPTIMIS) confirmed that compared with other treatments, switching to sorafenib immediately after TACE ineligibility improved OS (propensity score matched cohort: 15.2 vs. 11.8 months). ${ }^{34}$

Regarding liver function, one Japanese study confirmed that liver function was not preserved with continuing TACE treatment after TACE refractory; patients with TACE refractory who continued to receive TACE had a significantly shorter median time to liver dysfunction than did those who switched to sorafenib (17.0 vs. 29.8 months, $P=0.030){ }^{42}$ In another other study, patients with TACE refractory who underwent repeated TACE had a greater increase in Child-Pugh score compared with patients who were converted to sorafenib. ${ }^{43}$ Taken together, these two studies strongly suggest that repeated TACE leads to deterioration in liver function in patients who are deemed refractory to TACE.

\section{WHY IS "TACE REFRACTORY" EMPHASIZED NOW?}

At present, phase 3 trials have proven the statistical significance of five molecular target agents as both first-line (sorafenib and lenvatinib) and second-line (regorafenib, ramcirumab, and cabozantinib) treatments for patients with $\mathrm{HCC}^{9-14}$ These drugs have been approved worldwide. Moreover, on the basis of early-phase trials, the US Food and Drug Administration also approved two immune checkpoint inhibitors (nivolumab and pembrolizumab). ${ }^{44,45}$ Looking back at the results of the phase 3 trials in patients with HCC, both the testing and control arms had increased median OSs during the previous decade as a result of the treatments after progression. ${ }^{9,10,14,46,47}$ In the study of regorafenib after sorafenib in patients with HCC (RESORCE) trial, Finn et al. ${ }^{48}$ reported a median OS of 26.0 months for the regorafenib arm from the time sorafenib was started, although the included population in the trial was limited because of strict inclusion criteria. Several retrospective studies have reported that sequential therapies might have an impact on the survival of patients with advanced HCC. $^{49,50}$ In the next era, a major strategy in patients with HCC seems to be sequential treatment with systemic therapies, although different countries or regions have different regulations regarding the use of each drug. That being said, in TACE refractory patients, survival outcomes with systemic therapies are suggested to be longer than with treatment with a single agent, like sorafenib.

Moreover, when considering using two or more molecular target agents in the clinical treatment of identical patients with HCC, we should focus on maintaining liver function more than we did in the previous era. Liver function deterioration leads to missed opportunities to start or switch to systemic therapies. Several latest reports have demonstrated that the high-tumor-burden population of patients with intermediate-stage HCC (large size or/and a lot of nodules) were at high risk of liver function deterioration after TACE. ${ }^{51-53}$ Two retrospective studies, which criticized the Japan Society of Hepatology's definition of TACE refractory, reported that $20-25 \%$ of patients had decreased liver function and Child-Pugh class B or C at the time they were deemed TACE re-

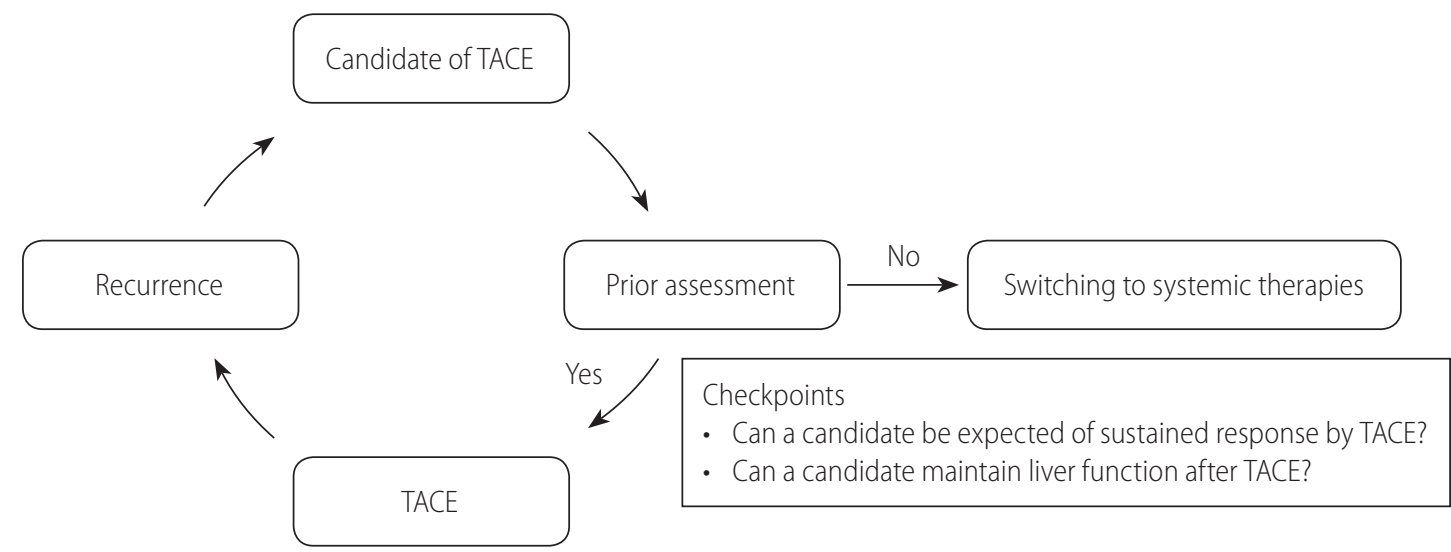

Figure 1. Concept of "Stop and think carefully before proceeding to each TACE." TACE, transarterial chemoembilization. 
Sadahisa Ogasawara, et al.

Best timing for switching to systemic therapies

fractory even though they were determined to have Child-Pugh class $A$ at the time of initial TACE. ${ }^{42,43}$ Taken together, the optimal timing to convert from TACE to systemic therapies may be when the patient's condition becomes unstable, which is different among individuals based on each patient's tumor status, treatment outcome of previous TACE and hepatic spare ability.

Recently, Kudo et al. ${ }^{54}$ compared survival outcomes between TACE and lenvatinib in seven patients with intermediate-stage HCC by using the propensity score matching method. In this study, the lenvatinib group had no history of receiving TACE. Despite the presence of several biases, the result might suggest the possibility that systemic therapies can become the initial treatment choice and may replace TACE in a limited population of patients with intermediate-stage HCC. A randomized controlled trial that compares systemic therapy and TACE will be carried out in the near future.

\section{STOP AND THINK CAREFULLY BEFORE PRO- CEEDING TO EACH TACE}

With the development of novel compounds and the improving survival outcomes of patients with HCC, current systemic therapies should be considered as a treatment option for unresectable HCC. Especially in patients with intermediate-stage HCC, who can expect long clinical courses with better prognosis compared with advanced-stage HCC, updated treatment strategies with multimolecular agents focusing on not only short-term outcomes but also foresight with long-term perspectives are required. A validity assessment of the TACE procedure should be recommended before proceeding to each TACE (Fig. 1). In cases where the effectiveness of TACE is not expected or chronic liver function deterioration may occur after TACE, conversion to systemic therapies should be considered. Although the definition of TACE refractory by the Japan Society of Hepatology is useful information, switching the timing of TACE to way before the patient's liver function deteriorates, taking into account both the high expectations of clinical outcome with current sequential therapies of molecular target agents and preventing hepatic spare abilities, may be better. Radiologists, who have the responsibility for TACE, and hepatologists or oncologists should communicate more closely and construct treatment strategies for patients with unresectable HCC who receive TACE with a view of the prospect to convert from TACE to systemic therapies.

\section{CONCLUSIONS}

The present guidelines recommend TACE as first-line treatment for patients with unresectable HCC without both MVI and EHM. Several novel compounds have shown survival benefits in patients with advanced HCC. Nowadays, sequential therapies with two or more agents have prolonged patients' survival outcomes and have become predominant treatment strategies among patients with HCC. The anticipated clinical impact of systemic therapies in patients with HCC has increased, and conversion from TACE to systemic therapies is now weighed more heavily. Before starting treatment with TACE, conversion to systemic therapies or not should be considered ("Stop and think carefully before proceeding to each TACE"). Looking ahead to the future of systemic therapies, it is now necessary to foster a greater understanding of preserving liver function during TACE treatments.

\section{Authors' contribution}

SS, YO, Keisuke Koroki, SM, HK, Kengo Kanayama, Kazufumi Kobayashi, SK, MN, Naoya Kanogawa, TS, TK, ES, SN, AT, TC, MA, JK designed the article. SS and YO took the lead in writing the manuscript. Naoya Kato supervised the manuscript. All authors provided critical feedback and approved the manuscript.

\section{Acknowledgements}

We would also like to thank Enago (www.enago.jp) for the English language review.

\section{Conflicts of Interest}

Sadahisa Ogasawara received honoraria from Bayer, Eisai, Eli Lilly, consulting or advisory fees from Bayer, Eisai, Merck \& Co., Inc., Chugai Pharma, Eli Lilly, AstraZeneca, and research grants from Bayer and Eisai. Yoshihiko Ooka received honoraria from Eisai. Naoya Kato received honoraria from Bayer and Eisai, consulting or advisory role from Bayer and Eisai, research funding from Bayer and Eisai. The other authors who took part in this study indicated that they did not have anything to declare regarding funding or conflict of interest with respect to this study.

\section{REFERENCES}

1. Bray F, Ferlay J, Soerjomataram I, Siegel RL, Torre LA, Jemal A. Global cancer statistics 2018: GLOBOCAN estimates of incidence and mortality worldwide for 36 cancers in 185 countries. CA Cancer 
J Clin 2018;68:394-424

2. Forner A, Reig M, Bruix J. Hepatocellular carcinoma. Lancet 2018;391:1301-1314.

3. Villanueva A. Hepatocellular carcinoma. N Engl J Med 2019;380: 1450-1462.

4. Omata M, Cheng AL, Kokudo N, Kudo M, Lee JM, Jia J, et al. AsiaPacific clinical practice guidelines on the management of hepatocellular carcinoma: a 2017 update. Hepatol Int 2017;11:317-370.

5. Marrero JA, Kulik LM, Sirlin CB, Zhu AX, Finn RS, Abecassis MM, et al. Diagnosis, staging, and management of hepatocellular carcinoma: 2018 practice guidance by the American Association for the Study of Liver Diseases. Hepatology 2018;68:723-750.

6. European Association for the Study of the Liver. EASL clinical practice guidelines: management of hepatocellular carcinoma. J Hepatol 2018;69:182-236.

7. Korean Liver Cancer Association; National Cancer Center. 2018 Korean Liver Cancer Association-National Cancer Center Korea practice guidelines for the management of hepatocellular carcinoma. Gut Liver 2019;13:227-299.

8. Kokudo N, Takemura N, Hasegawa K, Takayama T, Kubo S, Shimada $M$, et al. Clinical practice guidelines for hepatocellular carcinoma: the Japan Society of Hepatology 2017 (4th JSH-HCC guidelines) 2019 update. Hepatol 2019;49:1109-1113.

9. Llovet JM, Ricci S, Mazzaferro V, Hilgard P, Gane E, Blanc JF, et al. Sorafenib in advanced hepatocellular carcinoma. N Engl J Med 2008;359:378-390.

10. Cheng AL, Kang YK, Chen Z, Tsao CJ, Qin S, Kim JS, et al. Efficacy and safety of sorafenib in patients in the Asia-Pacific region with advanced hepatocellular carcinoma: a phase III randomised, doubleblind, placebo-controlled trial. Lancet Oncol 2009;10:25-34.

11. Bruix J, Qin S, Merle P, Granito A, Huang YH, Bodoky G, et al. Regorafenib for patients with hepatocellular carcinoma who progressed on sorafenib treatment (RESORCE): a randomised, double-blind, placebo-controlled, phase 3 trial. Lancet 2017;389:56-66.

12. Zhu AX, Park JO, Ryoo BY, Yen CJ, Poon R, Pastorelli D, et al. Ramucirumab versus placebo as second-line treatment in patients with advanced hepatocellular carcinoma following first-line therapy with sorafenib (REACH): a randomised, double-blind, multicentre, phase 3 trial. Lancet Oncol 2015;16:859-870.

13. Abou-Alfa GK, Meyer T, Cheng AL, El-Khoueiry AB, Rimassa L, Ryoo $B Y$, et al. Cabozantinib in patients with advanced and progressing hepatocellular carcinoma. N Engl J Med 2018;379:54-63.

14. Kudo M, Finn RS, Qin S, Han KH, Ikeda K, Piscaglia F, et al. Lenvatinib versus sorafenib in first-line treatment of patients with unresectable hepatocellular carcinoma: a randomised phase 3 noninferiority trial. Lancet 2018;391:1163-1173.

15. Park JW, Chen M, Colombo M, Roberts LR, Schwartz M, Chen PJ, et al. Global patterns of hepatocellular carcinoma management from diagnosis to death: the BRIDGE study. Liver Int 2015;35:2155-2166.

16. Llovet JM, Bruix J. Systematic review of randomized trials for unresectable hepatocellular carcinoma: chemoembolization improves survival. Hepatology 2003;37:429-442.

17. Takayasu K, Arii S, Ikai I, Omata M, Okita K, Ichida T, et al. Prospective cohort study of transarterial chemoembolization for unresectable hepatocellular carcinoma in 8510 patients. Gastroenterology 2006;131:461-469.

18. Takayasu K, Arii S, Kudo M, Ichida T, Matsui O, Izumi N, et al. Superselective transarterial chemoembolization for hepatocellular carcinoma. Validation of treatment algorithm proposed by Japanese guidelines. J Hepatol 2012;56:886-892.

19. Matsui 0. Current status of hepatocellular carcinoma treatment in Japan: transarterial chemoembolization. Clin Drug Investig 2012;32 Suppl 2:3-13.

20. Lencioni R, de Baere T, Soulen MC, Rilling WS, Geschwind JF. Lipiodol transarterial chemoembolization for hepatocellular carcinoma: a systematic review of efficacy and safety data. Hepatology 2016;64:106-116.

21. Varela $M$, Real MI, Burrel $M$, Forner $A$, Sala $M$, Brunet $M$, et al. Chemoembolization of hepatocellular carcinoma with drug eluting beads: efficacy and doxorubicin pharmacokinetics. J Hepatol 2007;46:474-481.

22. Lammer J, Malagari K, Vogl T, Pilleul F, Denys A, Watkinson A, et al. Prospective randomized study of doxorubicin-eluting-bead embolization in the treatment of hepatocellular carcinoma: results of the PRECISION V study. Cardiovasc Intervent Radiol 2010;33:41-52.

23. Dhanasekaran R, Kooby DA, Staley CA, Kauh JS, Khanna V, Kim HS. Comparison of conventional transarterial chemoembolization (TACE) and chemoembolization with doxorubicin drug eluting beads (DEB) for unresectable hepatocelluar carcinoma (HCC). J Surg Oncol 2010;101:476-480.

24. Golfieri R, Giampalma E, Renzulli M, Cioni R, Bargellini I, Bartolozzi $C$, et al. Randomised controlled trial of doxorubicin-eluting beads vs conventional chemoembolisation for hepatocellular carcinoma. $\mathrm{Br} J$ Cancer 2014;111:255-264

25. Matsui O, Miyayama S, Sanada J, Kobayashi S, Khoda W, Minami T, et al. Interventional oncology: new options for interstitial treatments and intravascular approaches: superselective TACE using iodized oil for HCC: rationale, technique and outcome. J Hepatobiliary Pancreat Sci 2010;17:407-409.

26. de Baere T, Arai Y, Lencioni R, Geschwind JF, Rilling W, Salem R, et al. Treatment of liver tumors with lipiodol TACE: technical recommendations from experts opinion. Cardiovasc Intervent Radiol 2016:39:334-343.

27. Sieghart W, Hucke F, Peck-Radosavljevic M. Transarterial chemoembolization: modalities, indication, and patient selection. J Hepatol 2015;62:1187-1195. 
Sadahisa Ogasawara, et al. Best timing for switching to systemic therapies

28. Raoul JL, Forner A, Bolondi L, Cheung TT, Kloeckner R, de Baere T. Updated use of TACE for hepatocellular carcinoma treatment: how and when to use it based on clinical evidence. Cancer Treat Rev 2019;72:28-36

29. Pua U, Teo CC, U PT, Quek LHH. Cone-beam CT acquisition during transradial TACE made easy; use of the swivel arm board. Br J Radiol 2018;91:20170248.

30. Liu FY, Li X, Yuan HJ, Guan Y, Wang MQ. Angio-computed tomograph-guided immediate lipiodol computed tomograph for diagnosis of small hepatocellular carcinoma lesions during transarterial chemoembolization. Chin Med J (Engl) 2018;131:2410-2416.

31. Piron L, Le Roy J, Cassinotto C, Delicque J, Belgour A, Allimant $C$, et al. Radiation exposure during transarterial chemoembolization: angio-CT versus cone-beam CT. Cardiovasc Intervent Radiol 2019:42:1609-1618.

32. Yamakado K, Miyayama S, Hirota S, Mizunuma K, Nakamura K, Inaba Y, et al. Hepatic arterial embolization for unresectable hepatocellular carcinomas: do technical factors affect prognosis? Jpn J Radiol 2012;30:560-566.

33. Ogasawara S, Chiba T, Ooka Y, Kanogawa N, Motoyama T, Suzuki $E$, et al. A randomized placebo-controlled trial of prophylactic dexamethasone for transcatheter arterial chemoembolization. Hepatology 2018;67:575-585.

34. Peck-Radosavljevic M, Kudo M, Raoul JL, Lee HC, Decaens T, Heo J, et al. Outcomes of patients (pts) with hepatocellular carcinoma (HCC) treated with transarterial chemoembolization (TACE): Global OPTIMIS final analysis. J Clin Oncol 2018;36(15_suppl):4018.

35. Miksad RA, Ogasawara S, Xia F, Fellous M, Piscaglia F. Liver function changes after transarterial chemoembolization in US hepatocellular carcinoma patients: the LiverT study. BMC Cancer 2019;19:795.

36. Hiraoka A, Kumada T, Kudo M, Hirooka M, Koizumi Y, Hiasa Y, et al. Hepatic function during repeated TACE procedures and prognosis after introducing sorafenib in patients with unresectable hepatocelIular carcinoma: multicenter analysis. Dig Dis 2017;35:602-610.

37. Piscaglia F, Ogasawara S. Patient selection for transarterial chemoembolization in hepatocellular carcinoma: importance of benefit/risk assessment. Liver Cancer 2018;7:104-119.

38. Kudo M, Izumi N, Kokudo N, Matsui O, Sakamoto M, Nakashima O, et al. Management of hepatocellular carcinoma in Japan: consensusbased clinical practice guidelines proposed by the Japan Society of Hepatology (JSH) 2010 updated version. Dig Dis 2011;29:339-364.

39. Kudo M, Matsui O, Izumi N, Kadoya M, Okusaka T, Miyayama $S$, et al. Transarterial chemoembolization failure/refractoriness: JSHLCSGJ criteria 2014 update. Oncology 2014;87 Suppl 1:22-31.

40. Raoul JL, Sangro B, Forner A, Mazzaferro V, Piscaglia F, Bolondi L, et al. Evolving strategies for the management of intermediate-stage hepatocellular carcinoma: available evidence and expert opinion on the use of transarterial chemoembolization. Cancer Treat Rev
2011;37:212-220.

41. Galle PR, Tovoli F, Foerster F, Wörns MA, Cucchetti A, Bolondi L. The treatment of intermediate stage tumours beyond TACE: from surgery to systemic therapy. J Hepatol 2017;67:173-183.

42. Ogasawara S, Chiba T, Ooka Y, Kanogawa N, Motoyama T, Suzuki $E$, et al. Efficacy of sorafenib in intermediate-stage hepatocellular carcinoma patients refractory to transarterial chemoembolization. Oncology 2014;87:330-341.

43. Arizumi T, Ueshima K, Minami T, Kono M, Chishina H, Takita M, et al. Effectiveness of sorafenib in patients with transcatheter arterial chemoembolization (TACE) refractory and intermediate-stage hepatocellular carcinoma. Liver Cancer 2015;4:253-262.

44. El-Khoueiry AB, Sangro B, Yau T, Crocenzi TS, Kudo M, Hsu C, et al. Nivolumab in patients with advanced hepatocellular carcinoma (CheckMate 040): an open-label, non-comparative, phase 1/2 dose escalation and expansion trial. Lancet 2017;389:2492-2502.

45. Zhu AX, Finn RS, Edeline J, Cattan S, Ogasawara S, Palmer D, et al. Pembrolizumab in patients with advanced hepatocellular carcinoma previously treated with sorafenib (KEYNOTE-224): a nonrandomised, open-label phase 2 trial. Lancet Oncol 2018;19:940952.

46. Johnson PJ, Qin S, Park JW, Poon RT, Raoul JL, Philip PA, et al. Brivanib versus sorafenib as first-line therapy in patients with unresectable, advanced hepatocellular carcinoma: results from the randomized phase III BRISK-FL study. J Clin Oncol 2013;31:3517-3524.

47. Cainap C, Qin S, Huang WT, Chung IJ, Pan H, Cheng Y, et al. Linifanib versus sorafenib in patients with advanced hepatocellular carcinoma: results of a randomized phase III trial. J Clin Oncol 2015;33:172-179.

48. Finn RS, Merle P, Granito A, Huang YH, Bodoky G, Pracht $M$, et al. Outcomes of sequential treatment with sorafenib followed by regorafenib for HCC: additional analyses from the phase III RESORCE trial. J Hepatol 2018;69:353-358.

49. Yoo C, Park JW, Kim YJ, Kim DY, Yu SJ, Lim TS, et al. Multicenter retrospective analysis of the safety and efficacy of regorafenib after progression on sorafenib in Korean patients with hepatocellular carcinoma. Invest New Drugs 2019;37:567-572.

50. Ogasawara S, Ooka Y, Itokawa N, Inoue M, Okabe S, Seki A, et al. Sequential therapy with sorafenib and regorafenib for advanced hepatocellular carcinoma: a multicenter retrospective study in Japan. Invest New Drugs 2020;38:172-180.

51. Arizumi T, Minami T, Chishina H, Kono M, Takita M, Yada N, et al. Time to transcatheter arterial chemoembolization refractoriness in patients with hepatocellular carcinoma in Kinki criteria stages B1 and B2. Dig Dis 2017;35:589-597.

52. Yasui Y, Tsuchiya K, Kurosaki M, Takeguchi T, Takeguchi Y, Okada M, et al. Up-to-seven criteria as a useful predictor for tumor downstaging to within Milan criteria and Child-Pugh grade deterioration after 
initial conventional transarterial chemoembolization. Hepatol Res 2018:48:442-450.

53. Eso Y, Takai A, Takahashi K, Ueda Y, Taura K, Marusawa H, et al. Combination of Mac-2 binding protein glycosylation isomer and up-to-seven criteria as a useful predictor for Child-Pugh grade deterioration after transarterial chemoembolization for hepatocellular carcinoma. Cancers (Basel) 2019;11:405.

54. Kudo M, Ueshima K, Chan S, Minami T, Chishina H, Aoki T, et al. Lenvatinib as an initial treatment in patients with intermediatestage hepatocellular carcinoma beyond up-to-seven criteria and Child-Pugh a liver function: a proof-of-concept study. Cancers (Basel) 2019;11:1084. 